\title{
Avoidance learning in a black and white shuttlebox*
}

\author{
SEWARD A. MOOT, KELLY NELSON, and ROBERT C. BOLLES \\ University of Washington, Seattle, Washington 98195
}

\begin{abstract}
The study explores possible reasons for the poor avoidance performance of rats in a heterogenious black-white shuttlebox reported by Weisman, Denny, and Zerbolio (1967). Little evidence of this decrement was found when rats were free to make intertrial responses. There was a general deficit in learning when a door was used to prevent intertrial responding, however, and this deficit was greater when the rats were confined in the black-white apparatus.
\end{abstract}

One line of evidence that tends to support Denny's (1971) relaxation theory of avoidance learning is the finding of Knapp (1965) and Reynierse and Rizley (1970) that the learning of jump-out avoidance and one-way avoidance, respectively, were facilitated by making the safe part of the apparatus perceptually different from the dangerous part. If the safe region is different from the danger region, it is less likely to generalize to the shock region and compete with the avoidance response. The shuttlebox situation is somewhat more complicated in Denny's (1971) analysis because it provides no really safe place; there is no place free from shock. Rather than a specific place, there is a specific period of time following the animal's response that is associated with relaxation. The animal's best chance to solve the problem is to be unable to discriminate one end of the shuttlebox from the other, and any experimental manipulation which emphasizes the spatial properties of the shuttlebox is likely to impair avoidance acquisition. Thus the discovery of Weisman, Denny, and Zerbolio (1967) that avoidance learning is relatively poor with intertrial intervals less than $2 \mathrm{~min}$ in a shuttlebox that is white on one end and black on the other is consistent with the requirements of relaxation theory.

One purpose of the present study was to replicate this important finding. At the same time, we wanted to examine more closely the conditions under which this poor performance occurs. If the rat's task in the shuttlebox is, as Denny proposes, to have relaxation responses conditioned more or less equally to all parts of the apparatus, then it should make little difference where relaxation occurs. Specifically, it should make little difference if the animal is confined to one end of the box after a run or if it is free to make intertrial responses (ITR). In the present experiment, we explore the effects of ITRs on shuttlebox avoidance.

\section{METHOD}

Subjects

The Ss were 24 naive female rats of Long-Evans descent,

*Supported by Research Grant GB-20801 from the National Science $F$ oundation. R equests for reprints should be addressed to Robert C. Bolles, Department of Psychology, University of Washington, Seattle, Washington, 98195. approximately 100 days old. They were maintained on ad lib food and water throughout.

\section{Apparatus}

The apparatus was an automated shuttlebox $90 \mathrm{~cm}$ long, $12 \mathrm{~cm}$ wide, and $18 \mathrm{~cm}$ high housed in a sound-deadened box. Constant illumination was provided by a $15-\mathrm{W}$ bulb located above the center. A ventilation fan gave a constant background noise of approximately $68 \mathrm{~dB}$, and an electric buzzer used as the CS increased the sound level to approximately $78 \mathrm{~dB}$. The floor was made of $1-\mathrm{cm}$ stainless steel bars spaced $2.5 \mathrm{~cm}$ center to center. Shock at $.8 \mathrm{~mA}$ was provided by a Grason-Stadler source and scrambler. The apparatus was painted white, but a Masonite insert could be placed inside it to make it white on one end and black on the other, as Weisman et al (1967) had done.

\section{Procedure}

Rats were randomly divided into four groups constituting a factorial design. Two groups (white-white and black-white) were trained with no door so that running could occur at any time. The other two groups (white-white-door and black-white-door) were run with a door painted on each side to match the corresponding end of the apparatus so as to approximate the conditions of the Weisman et al study. Under the black-white condition, black and white were fixed locations for a given animal The door was lowered immediately after an avoidance $\left(R_{a}\right)$ or escape $\left(R_{e}\right)$ occurred and was raised again at the next CS onset. All animals were given 30 training trials in a single session. The interstimulus interval was $10 \mathrm{sec}$, and the variable intertrial interval averaged $80 \mathrm{sec}$. On trials where the rat failed to avoid, the CS terminated with $\mathrm{R}_{\mathrm{e}}$; on avoidance trials it terminated with $R_{\mathrm{a}}$.

\section{RESULTS}

The number of $R_{a}$ s for each $S$ over the 80 training trials is shown in Fig. 1. An analysis of variance of these data showed that the overall main effects of color conditions were highly significant $(\mathrm{F}=14.88, \mathrm{df}=1 / 20$, $\mathrm{p}<.05)$. Individual comparisons with Duncan's new multiple range test indicated that the color conditions only had a significant effect upon the groups with the door. Thus the color of the shuttlebox compartments had little or no effect on the performance of $R_{a}$ when rats were free to make ITRs. Both groups without the door showed relatively good avoidance learning. The severe decrement in avoidance performance under the black-white-door condition originally reported by Weisman et al (1967) was also replicated. But it now appears that this decrement is primarily a result of 


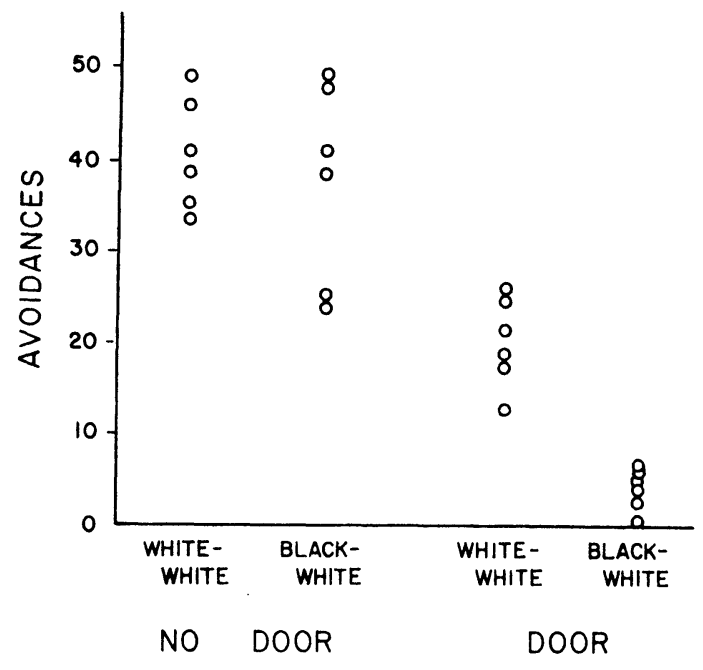

Fig. 1. Number of avoidances in 80 trials for individual Ss.

confining animals after a response and not, as Denny (1971) has proposed, just a consequence of the two compartments being easily discriminable.

It might be thought that the occurrence of ITRs in the black-white group would reflect the frightened rat's tendency to approach dark areas (e.g., Reynierse \& Rizley, 1970). That is, the black-white animals might have been expected to make the preponderance of their ITRs so as to return to the black end of the shuttlebox. But this was not the case; none of the black-white animals showed an appreciable black-going bias. Although most rats showed some such bias, it more frequently favored returning to white than returning to black. It might also be thought that if the frightened rat has a tendency to approach or stay in a black compartment, the black-white group would be more likely to make an $R_{a}$ on those trials when it could run from white to black. But again, such a bias was not evident in the data. Avoidances to black constituted only $52 \%$ of the total $\mathrm{R}_{\mathrm{a}} \mathrm{s}$ in the black-white group and only $35 \%$ in the black-white-door group. Finally, although the groups were too small to estimate correlations reliably, the correlations between number of ITRs and number of $R_{a}$ s were suggestive, viz., $r=.55$ for the black-white group and -.03 for the white-white group.

\section{DISCUSSION}

Many years ago Coppock and Mowrer (1947) showed that the prevention of intertrial responding could seriously interfere with shuttlebox avoidance learning in rats. They proposed that the ITRs were a form of rehearsal, a means whereby the rat is better able to remember what the appropriate response is. Bolles and Grossen (1970) suggested that the rat is better able to learn about safety in an avoidance situation when it is permitted to produce cues to safety by its own behavior. Perhaps this interpretation is appropriate, and perhaps the present result merely indicate that a further qualification should be added, namely, that it is also important that the animal be free to produce safety by making a response whenever the stimulus conditions, whatever they might be, that produce the response occur.

Implied in Denny's (1971) analysis is the interpretation that response prevention guarantees relaxation becoming conditioned to prevailing stimuli. This is a possibility, but it also seems possible that confinement could work against the conditioning of relaxation. It might do so, for example, if the animal was not relaxing during the confinement. Suppose that, for some reason, the animal encounters conditions which would ordinarily produce running. If it is confined, perhaps freezing rather than relaxation becomes conditioned to situational cues.

There was no indication here of an overall black-going bias in either ITRs or $\mathrm{R}_{\mathrm{a}} \mathrm{s}$. But we may suppose that a color bias exists early in training, i.e., after the first few shocks, and that these preferences can affect behavior in situations where the $R_{a}$ is rapidly acquired (Knapp, 1965; Reynierse \& Rizley, 1970). And we may also suppose that the mechanisms responsible for learning in the shuttlebox are so subtle that they emerge only after the first few traumatic trials in which the rat's initial response tendencies are suppressed.

The scanty data do not justify much speculation about why confinement produces an especially serious failure in black-white shuttlebox. But we cannot accept Denny's explanation that painting the two ends of the shuttlebox makes them discriminably different. One reason for skepticism is that we doubt the rat is often confused about the two ends even in the traditional homogenious shuttlebox. A second reason is that our results indicate no failure of avoidance learning in the black and white apparatus unless ITRs are prevented. A third reason is that Weisman et al (1967) found relatively good learning in the absence of ITRs in a black and white shuttlebox when they used a sufficiently long intertrial interval $(200 \mathrm{sec})$.

We would suggest as a new hypothesis a compromise formulation between Denny's relaxation hypothesis and the cognitive position of Bolles (1972). We suggest that the best account of why the rats runs in a shuttlebox is that the other end of it looks safe. This perception, we assume is partly inherent in the physical situation but it results mainly from the rat repeatedly encountering periods free from shock at the other end of the box. We assume further that the perception of "the other end" is a rather delicate matter for the rat, but that it can be greatly facilitated by letting the rat explore the apparatus during the intertrial interval, and that it can be blocked (overshadowed) by painting the two ends in a manner for which the rat has an innate perception. When the apparatus is colored black at one end and white at the other, the rat continues to perceive it as black and white and cannot readily learn to see it as this end and the other end-unless the rat is free to explore it.

\section{REFERENCES}

Bolles, R. C. Reinforcement, expectancy, and learning. Psychological R eview, 1972, 79, 349-409.

Bolles, R. C., \& Grossen, N. E. Function of the CS in shuttlebox avoidance learning by rats. Journal of Comparative \& Physiological Psychology, 1970, 70, 165-169.

Coppock, H., \& Mowrer, O. H. Intertrial responses as "rehearsal": A study of "overt thinking" in animals. American Journal of Psychology, 1947, 60, 608-616.

Denny, M. R. Relaxation theory and experiments. In F. R. Brush (Ed.) Aversive conditioning and learning. New York: Academic Press, 1971.

Knapp, R. K. Acquisition and extinction of avoidance with similar and different shock and escape situations. Journal of Comparative \& Physiological Psychology, 1965, 60, 272-273.

Reynierse, J. H., \& Rizley, R. C. Relaxation and fear as determinants of maintained avoidance in rats. Journal of Comparative \& Physiological Psychology, 1970, 72, 223-232.

Weisman, R. G., Denny, M. R., \& Zerbolio, D. J. Discrimination based on differentials nonshock confinement in a shuttle box. Journal of Comparative \& Physiological Psychology, 196 7, 63 , 34-38.

(R eceived for publication August 21, 1974.) 